\title{
STUDI DESKRIPTIF PENDIDIKAN KARAKTER SD TARUNA BAKTI BANDUNG
}

\author{
Eneng Nurlaili Wangi ${ }^{1}$, Siti Mutya Lutfiani ${ }^{2}$ \\ Fakultas Psikologi, Universitas Islam Bandung, \\ Email: ${ }^{1}$ nurlailiyunar@gmail.com, ${ }^{2}$ tyaalutfiani5@gmail.com
}

(C2018 -JPT Fakultas Psikologi Universitas Negeri Makassar. Ini adalah artikel dengan

akses terbuka di bawah licenci CC BY-NC-4.0 (https://creativecommons.org/licenses/by-nc/4.0/ ).

\begin{abstract}
ABSTRAK
Kasus kriminalitas yang dilakukan oleh anak semakin marak dan meningkat setiap tahunnya, hal ini menunjukan krisis moral pada anak-anak Indonesia. Sekolah mempunyai peran yang besar dalam hal tersebut, tidak hanya memfokuskan pada pencapaian akademik melainkan pada pengembangan spiritual dan emosional, hal ini menunjukan bahwa pendidikan karakter pada tiap sekolah itu penting. SD Taruna Bakti sudah menerapkan pendidikan karakter sejak pertama kali dibangun dan programnya dikembangkan kembali sejak 2012. Tujuan dari penelitian ini yaitu menggambarkan penerapan pendidikan karakter di SD Taruna Bakti Bandung. Alat ukur yang digunakan dalam kecerdasan emosional adalah dengan menggunakan Twelve Component Assesment and Planning (TCAP) yang dirumuskan oleh Thomas Lickona. Subjek penelitan berjumlah 24 orang. Metoda yang digunakan dalam penelitian ini adalah deskriptif kuantitatif. Hasil menunjukan sebanyak 24 staf pengajar (100\%) menyatakan bahwa pendidikan karakter di SD Taruna Bakti efektif.
\end{abstract}

Kata Kunci : Pendidikan karakter, SD Taruna Bakti

\begin{abstract}
Crime cases committed by children are increasing every year, this shows a moral crisis in Indonesian children. Schools have a large role in this regard, not only focusing on academic achievement on spiritual and emotional development, it refers to Character Education in every school that is important. Taruna Bakti Elementary School has implemented education since it was first built and the program has been redeveloped since 2012. The purpose of this study is to study the application of educational character in Taruna Bakti Elementary School in Bandung. The measuring tool used in emotional intelligence is to use the Twelve Assessment and Planning Components (TCAP) formulated by Thomas Lickona. The subject of research is the victory of 24 people. The method used in this research is quantitative descriptive. The results showed that 24 teaching staff (100\%) were declared as character education in SD Taruna Bakti effectively.
\end{abstract}

Keywords: Character education, Taruna Bakti Elementary School

\section{PENDAHULUAN}

Apabila setiap individu ingin memperbarui dan meningkatkan kualitas dalam masyarakat, hal yang pertama harus dilakukan yaitu membesarkan generasi anak - anak dengan kultur moral kuat (Lickona, 2004). Pendidikan karakter adalah usaha disengaja untuk membantu individu agar dapat memahami, memperhatikan, serta segala usaha yang dilakukan untuk menanamkan nilai tertentu yang akan menjadi ciri khas setiap individu dalam berpikir dan berperilaku. Secara sederhana, pendidikan 
karakter dapat didefinisikan sebagai segala usaha yang dilakukan untuk memengaruhi karakter (Lickona,2012).

Sebuah penelitian yang dilakukan oleh Beninga, Berkowitz, Kuehn, dan Smith (2003) memperlihatkan bahwa beberapa Sekolah Dasar di California memberikan tuntutan dalam belajar di sekolah dengan tidak hanya berfokus pada pencapaian akademik saja, namun juga keharsan untuk memiliki karakter positif yang kuat. Hasilnya menunjukan bahwa siswa yang memiliki karakter positif yang tinggi berkecenderungan akan mempunyai orientasi berprestasi akademik yang tinggi dengan tidak menghiraukan skor IQ yang dimiliki. Hal ini membuktikan bahwa karakter yang positif dan juga kuat lebih memberikan pengaruh pada keberhasilan dalam pencapaian akademik dibandingkan potensi kecerdasan saja (Martiarini, 2016).

SD Taruna Bakti Bandung sudah menerapkan program pendidikan karakter sejak tahun 2012 dan menjadi salah satu sekolah pertama yang menerapkan program Bandung Masagi. Bandung Masagi adalah suatu model pendidikan karakter berbasis kearifan lokal, yang dirumuskan oleh Dinas Pendidikan Kota Bandung pada tahun 2016. Program Bandung Masagi idealnya wajib diterapkan oleh seluruh sekolah yang berada di kota Bandung.
Berdasarkan dari hasil wawancara dengan guru Bimbingan Konseling di SD Taruna Bakti menyatakan bahwa pendidikan karakter di sekolah ini dituangkan menjadi program berbentuk mata pelajaran wajib, dan juga diaplikasikan dalam berbagai kegiatan di sekolah. Mata pelajaran ini wajib diikuti oleh seluruh siswa, dimulai dari siswa kelas 1 hingga kelas 6. Program pendidikan karakter ini sendiri mulai benar benar dirancang dan diterapkan pada tahun 2012 . Pengaplikasian dalam kegiatan di sekolah, salh satunya dengan menyiapkan satu buah buku yang dinamakan buku BK di setiap kelas. Buku tersebut berisikan mengenai perkembangan masing masing siswa selama berada di kelas. Buku ini diisi oleh setiap guru yang mengajar dikelas. Buku tersebut terdiri dari komponen komponen perkembangan belajar, sosial, pengembangan diri, dan karir yang ditujukan untuk siswa. Hal ini diharapkan agar baik pengajar maupun orang tua mengetahui perkembangan perilaku anak selama berada di sekolah.

Melalui program yang sudah disusun dan direncanakan oleh pihak sekolah, diharapkan agar siswa dapat membuka diri dan dapat menggali sisi dalam diri siswa yang bisa dikembangkan. Sejauh ini ratarata siswa sudah dapat memenuhi tujuan tersebut. Berdasarkan dari data yang didapatkan, pendidikan karakter di SD 
Taruna Bakti Bandung sudah mencirikan pendidikan karakter yang diungkapkan oleh Thomas Lickona, dimana pendidikan karakter itu mencakup tiga aspek yaitu moral knowing, moral feeling dan moral behavior. Aspek moral knowing mencakup kesadaran moral, pengetahuan nilai moral, penentuan perspektif, pemikiran moral, pengambilan keputusan, dan pengetahuan pribadi. Pada aspek moral feeling mencakup hati nurani, harga diri, empati, mencintai hal yang baik, kendali diri, dan kerendahan hati. Sedangkan pada aspek moral behavior mencakup kompetensi, keinginan dan kebiasaan.

Berdasarkan penuturan beberapa guru, program pendidikan karakter di sekolah ini sudah jauh lebih baik dibandingkan dengan sekolah lainnya. Salah satu guru mengatakan bahwa jarang sekali ada sekolah yang bahkan menjadikan Pendidikan karakter sebagai mata pelajaran wajib, menurutnya sekolah ini telah berhasil mengoptimalkan pendidikan karakter di sekolah karena selain melalui pengaplikasian sehari-hari, juga diberikan melalui materi ajar. Di sisi lain, program ini masih membutuhkan beberapa hal yang harus dibenahi karena belum terlaksana dengan baik.

Sebuah penelitian yang dilakukan oleh Marvin Berkowitz (Adhim, 2012) mengenai pendidikan karakter terungkap bahwa adanya peningkatan motivasi siswa dalam sekolah dalam meraih prestasi akademik pada sekolah yang menerapkan pendidikan karakter dan kelas kelas yang secara kompherensif menerapkan pendidikan karakter menunjukan adanya penurunan yang drastis pada perilaku negatif siswa yang dapat menghambat keberhasilan akademik. Pendidikan karakter membuat seorang anak menjadi cerdas emosinya. Meskipun, di SD Taruna Bakti pendidikan karakter telah digencarkan dengan rutin baik melalui pembiasaan dan melalui kurikulum dalam bentuk mata pelajaran, akan tetapi masih terdapat siswa siswa yang masih memperlihatkan perilaku negatif. Berdasarkan uraian tersebut peneliti tertarik untuk mengambil judul "Studi Deskriptif Pendidikan Karakter di SD Taruna Bakti Bandung”

\section{METODE}

Penelitian ini merupakan penelitian deskriptif kuantitatif. Penelitian deskriptif adalah yang penelitian yang bertujuan dalam melakukan deskripsi dan gambaran pada data yang telah dikumpulkan tanpa membuat kesimpulan. Sedangkan penelitian kuantitatif yaitu penelitian yang prosedurnya menggunakan statistic (Sugiyono, 2015). Penelitian ini bertujuan untuk mendapatkan gambaran penerapan pendidikan karakter di SD Taruna Bakti Bandung. 
Alat ukur yang digunakan dalam kecerdasan emosional adalah dengan menggunakan Twelve Component Assesment and Planning (TCAP) yang dirumuskan oleh Thomas Lickona dengan pertimbangan, tujuan peneliti untuk melihat implementasi atau penerapan program pendidikan karakter di SD Taruna Bakti. 36 item Twelve Component Assesment and Planning (TCAP) menunjukan bahwa 73 item dikatakan valid, sedangkan 36 item dikatakan tidak valid. Peneliti membuang sebanyak 36 item yang tidak valid kemudian melakukan uji reliabilitas menggunakan 73 item Twelve Component Assesment and Planning (TCAP) yang valid.

Jumlah Populasi dalam penelitian ini adalah staf dan pengajar yang berjumlah 24 orang. Peneliti menggunakan studi populasi dimana studi populasi merupakan penelitian yang mengambil data dari seluruh elemen di dalam wilayah penelitian (Arikunto, 2006). Studi Populasi dilakukan karena keterbatasan jumlah subjek yaitu sebanyak 24 orang.

Uji validitas yang digunakan untuk menguji instrument alat ukur dalam penelitian ini adalah Product Moment dari Karl Pearson sedangkan Uji reliabilitas yang digunakan untuk menguji instrument alat ukur dalam penelitian ini menggunakan teknik teknik Alpha
Cronbach yang dibantu dengan program IBM SPSS Statistics 21.0.

\section{HASIL PENELITIAN}

Berikut adalah kategorisasi dari hasil pengolahan data pendidikan karakter SD Taruna Bakti Bandung:

Tabel 1. Kategori hasil analisis data deskriptif

\begin{tabular}{ccc}
\hline Implementasi & Kategori & $\begin{array}{c}\text { Persentase } \\
\text { dari } \\
\text { jawaban } \\
\text { responden }\end{array}$ \\
\hline $\begin{array}{c}\text { Pelaksanaan } \\
\text { Pendidikan } \\
\text { Karakter } \\
\text { Moral } \\
\text { Knowing } \\
\text { Moral }\end{array}$ & Tinggi & $100 \%$ \\
$\begin{array}{c}\text { Feeling } \\
\text { Moral Action }\end{array}$ & Tinggi & $100 \%$ \\
\hline
\end{tabular}

Berdasarkan data di atas, terlihat bahwa program pendidikan karakter di SD Taruna Bakti dilaksanakan oleh sekolah, beserta implikasi moral knowing, moral feeling dan moral action.

\section{DISKUSI}

Berdasarkan hasil pengolahan data, terlihat bahwa pendidikan karakter di SD Taruna Bakti berjalan dengan baik. Sekolah ini mempunyai program pendidikan karakter yang sudah sejak 2012 diterapkan secara intens baik dalam bentuk pembiasaan pembiasaan maupun dalam bentuk mata pelajaran. Disamping itu penguatan karakter melalui ekstrakulikuler 
juga sangat digencarkan, salah satunya dalam ekstrakulikuler pramuka. Program pendidikan karakter di sekolah ini juga sudah mengikuti program pemerintah yaitu program Bandung Masagi dan PPK. Guru dan staf-staf pengajar di sekolah ini dapat menciptakan suasana yang kondusif serta mengarahkan siswa ke arah yang lebih baik sesuai dengan visi dan misi sekolah ini yaitu menciptakan siswa siswi yang jujur, toleransi disiplin, tanggung jawab, mandiri, peduli lingkungan, dan peduli sosial.

Pada aspek moral knowing ditunjukkan dalam bentuk mengulas perilaku dan mengevaluasi perilaku diri sendiri secara kritis. Mengembangkan pengetahuan moral pribadi mengikutsertakan hal menjadi sadar akan kekuatan dan kelemahan akan karakter individual kita dan bagaimana mengkompensasi kelemahan kita diantara karakter tersebut (Lickona, 2012). Salah satu kegiatan pada program pendidikan karakter di sekolah ini yaitu setiap hari siswa rutin untuk mengerjakan "selfreport" yang beirsikan kegiatan sehariharinya dan perasaan siswa-siswanya ketika sedang melakukan kegiatan tersebut. Self- report tersebut akan dikumpulkan keeseokan harinya dan diceritakan didepan teman-teman kelasnya. Kegiatan tersebut bertujuan untuk mengekspresikan perasaan yang dirasakan oleh siswa-siswanya agar tidak memendam.
Didalam aspek ini terdapat beberapa sub-aspek diantaranya Teacher as Caregiver, Model, \& Mentor, Ethical Reflection, Teaching Conflict Resolution, dan Creating a Positive Moral Culture in The School. Dalam aspek ini keempatnya sudah berjalan secara efektif namun pada sub-aspek Creating a Positive Moral Culture in The School masih ada salah satu staf/ pengajar yang menyatakan tidak efektif. Guru-guru serta staff pengajar SD Taruna Bakti sudah dapat menciptakan lingkungan yang baik dan nyaman, memberikan pelayanan, memberikan kesempatan kepada siswa untuk peduli terhadap orang lain.Selain itu mereka juga sudah memberikan kesempatan yang baik pada orang tua murid untuk berpartisipasi dalam pengembangan karakter siswa, baik pengembangan karakter yang terjalin disekolah maupun di lingkungan rumahnya. Meskipun ada salah satu staff yang menyatakan bahwa sekolah ini belum maksimal dalam menciptakan lingkungan yang dapat mengembangkan karakter siswa yang baik.

Pada aspek moral feeling mengulas kebaikan moral yang diperlukan untuk mengontrol emosi yang berlebihan. Kendali diri dapat membantu seseorang beretika bahkan ketika seseorang terseut tidak menginginkannya. membantu individu untuk beretika, juga menahan diri agar tidak memanjakan diri sendiri 
(Lickona, 2012). Salah satu kegiatan pada program pendidikan karakter di sekolah ini yaitu siswa diminta untuk menggambar atau menulis apapun namun dengan aturan tidak boleh dihapus atau diperbaiki. Kegiatan ini bertujuan agar siswa mampu mengendalikan emosi didalam dirinya agar tidak semena-mena diungkapkan, karena akan terdapat konsekuensi dari setiap perilakunya. Didalam aspek ini terdapat beberapa sub-aspek diantaranya Caring Classroom Community, Character Based Discipline, Democratic Classroom Environment, dan Caring Beyond the Classroom. Dalam aspek ini keempatnya sudah berjalan secara efektif namun pada sub-aspek Creating a Positive Moral Culture in The School masih ada salah satu staf/ pengajar yang menyatakan tidak efektif.

Sebagian guru-guru serta staff pengajar SD Taruna Bakti dapat menciptakan sebuah lingkungan kelas yang demokratis, melibatkan siswa dalam pengambilan keputusan dan bertanggung jawab. Hal ini dapat dilihat melalui observasi guru pada siswa dimana siswa dapat berpartisipasi dalam aturan-aturan yang berlaku di sekolah serta siswa dapat mematuhi dengan baik terhadap aturanaturan tersebut. Namun beberapa guru maupun staf pengajar menyatakan bahwa masih ada siswa-siswa yang masih tidak memahami aturan, melanggar aturan, dan tidak mempertanggung jawabkan atas perilaku melanggar aturannya

Pada aspek moral action merupakan hasil dari moral knowing dan moral feeling. Individu mungkin tahu apa yang harus dilakukan, merasakan apa yang harus dilakukan, namun masih gagal menerjemahkan pikiran dan perasaan kedalam tindakan (Lickona,2012). Salah satu kegiatan pada program pendidikan karakter di sekolah ini yaitu rutinnya kegiatan konsultasi antara pengajar (khususnya guru BK) dengan para siswanya. Konsultasi ini didasarkan pada pengisian buku BK yang disediakan dalam setiap kelas dan setiap siswa berdasarkan aspek-aspek perkembangannya maupun perilaku siswa ketika berada di dalam kelas. Selain mengenai aspek-aspek tersebut siswa juga diminta untuk menyatakan cita-cita atau tujuan yang ingin dicapainya dan hal apa yang sudah dilakukannya.

Aspek-aspek di atas tidak dapat berdiri sendiri-sendiri, namun saling berkaitan antara satu dengan yang lainnya. Ketiga aspek tersebut itulah yang membentuk pendidikan karakter di SD Taruna Bakti. Secara keseluruhan tersebut mencerminkan pendidikan karakter di SD Taruna Bakti sudah berjalan secara efektif.

Dalam mengembangkan karakter anak yang baik, pendidikan karakter tidak hanya didukung melalui lembaga pendidikan saja 
seperti sekolah melainkan peran keluarga juga sangat dibutuhkan, terlebih kerjasama antar keduanya. Sekolah idealnya selain membimbing para siswanya melalui pembiasaan-pembiasaan maupun kurikulum, tapi juga harus memberikan kesempatan dan fasilitas bagi orang tua urid untuk ikut berpartisispasi dalam perkembangan anak. Dengan adanya kerjasama antar keduanya, kekuatan yang sesungguhnya dapat dimunculkan untuk meningkatkan nilai moral sebagai seorang manusia dan untuk mengangkat kehidupan moral di negeri ini. Sebuah komunitas yang memiliki moral di lingkungan sekolah yang menyediakan suatu bentuk dukungan akan kebutuhan sekolah untuk melaksanakan pendidikan karakter secara efektif (Lickona, 2012).

Menurut Etzioni sekolah berperan sentral dalam membina karakter dengan menanamkan disiplin dan empati, yang pada gilirannya memungkinkan keterlibatan tulus terhadap nilai peradaban dan moral. Dengan berbuat begitu, tidaklah cukup menceramahi anak dengan nilainilai akan tetapi perlu dengan mempraktikannya. Para guru mengajarkan dan memberi kesempatan kepada murid untuk mengenak diri dan perasaa mereka. Dalam arti ini, keterampilan sosial bergandengan tangan dengan pendidikan karakter, demi pertumbuhan moral dan demi warga masyarakat (Goleman,2000).
Penelitian ini diharapkan bagi sekolah baiknya mempertahankan dan meningktakan kembali kualitas program program pendidikan karakter yang ada di SD Taruna Bakti. Kemudian bagi peneliti, studi penelitian ini baiknya menambahkan persepsi dari siswa dan juga orang tua.

\section{DAFTAR PUSTAKA}

Adhim, Fauzan (2012). Hubungan Pendidikan Karakter terhadap Kecerdasan Emosional pada Mahasiswa Fakultas Ekonomi Universitas Kanjuruhan Malang. Malang: Universitas Kanjuruhan Malang

Ananda, Rizal. (2018). Duh! Angka Anak Kesandung Hukum Masih Sangat Tinggi https://www.indometro.id/2018/07/d uh-angka-anak-kesandung-hukummasih.html (akses 23 Desember 2018)

Fruehling, R. \& Oldham, N. (1990). Your Attitude Counts. St. Paul, MN: Paradigm Publishing Inc

Kementerian Pendidikan Nasional. (2010). Pengembangan Pendidikan Budaya dan Karakter Bangsa. Jakarta: Kementerian Pendidikan Nasional Badan Penelitian dan Pengembangan Pusat Kurikulum.

Goleman, Daniel. (2002). Emotional Intelligence (terjemahan). Jakata: PT Gramedia Pustaka Utama.

Hurlock, Elizabeth B. (2011). Psikologi Perkembangan: Suatu Pendekatan Sepanjang Rentang Kehidupan. Jakarta: Erlangga.

Lickona, Thomas. (2012). Mendidik untuk Membentuk Karakter. Terjemahan Juma Abdu Wamaungo. (2016). Jakarta: Bumi Aksara 
Rice, DM (2006). An Examination of Emotional Intelligence: It's Relationship to Academic Achievement in Army JROTC and The Implications for Education. Minneapolis : Capella University

Syarif, K. (2015). Bahan Ajar Pendidikan Budi Pekerti. Medan: Universitas Negeri Medan Medan.

Sugiyono. 2015. Metode Penelitian Pendidikan (Pendekatan Kuantitatif, Kualitatif dan $R \& D$ ). Bandung : ALFABETA
Suparno, P. (2001). Teori Perkembangan Kognitif Jean Piaget. Jogjakarta: Kanisius

Ulutas, I., \& Omeroglu, E. (2007). The effects of an emotional intelligence education program on the emotional intelligence of children. Social Behavior and Personality, 35(10), 1365- 1372.

Zahra, Nadia. (2014) Kasus Kriminalitas Anak Akibat Kacaunya Sistem Pendidikan di https://megapolitan.kompas.com/rea d/2014/05/12/1304427/Kasus.Krimi nalitas.Anak.Akibat.Kacaunya.Siste m.Pendidikan (akses 23 Desember 2018). 